Elżbieta Pakszys

\title{
THE MAIN EPISTOMOLOGICAL ASSUMPTIONS OF CONTEMPORARY BIOLOGY (A SURVEY)
}

Cognitive condition of any scientific domain depends on its location among other fields of study, since relationships with the closest „neighbors” supplies, so it seems, fruitful analogies in executing the most important scientific functions: description, explanation and pre/postdiction. This way acquired interdisciplinary knowledge has its contribution in the ideal of objectivity, most crucial in creating the image of fully matured science.

This does not mean however, that we are dealing with the relationships abandoned of any limits between different scientific disciplines today. Quite contrary, specialization, peculiarity or autonomy of study seems to be equally justified feature of every advanced research, acquired especially through different methods and interpretation, invented and applied to various objects of study. Certainly, both reciprocal currents tend to shape contemporary research in all natural history. In this essay however, I will try to indicate only these concerning biology.

Science of life reflects from one hand strong tendency to physics-chemical reductionism, from another one, it tends to preserve its autonomous way of interpretation expressing characteristic position of life, its general object of study. Organic-living phenomena we locate usually somehow in between non-organic and social/human objects. It seems that this general statement determines choice of the issues taken into consideration under the name of epistemological assumptions of biology.

Among the most important presuppositions of this domain I see, first of all, the problems of research strategy, namely peculiar to biology dualism of methods, or complementarity between reductionism and its adversary, so called compositionism. Interdisciplinary character of these procedures should be stressed, however, complementarity means here seeking of some balance between both tendencies.

Another set of asumptions which shape contemporary biological interpretations consist of the problems concerning evolutional explanation, so 
16 indispensable to living phenomena. Only analysis of peculiar to biology compositionism, i.e. holistic, historical/evolutional way of explanation, shows the place for partial, reductionist interpretations.

In the conclusion we will be dealing with considerations of supposedly the most basic nature i.e. concerning ontological issues in describing and explaining biological objects and the way laws and theories operate in scientific action. We will try also to evaluate tentatively biological methods of study.

i.

According to a notion commonly spread among researchers (biologists and methodologists) contemporary biology does not meet the standard of methodologically matured science, i.e. accomplishing explanation and prediction through laws and theories, because of the ascertained excess of descriptive and classificatory procedures in it. The generalizations (laws and theories) formulated within it are charcterised by low level of universality since they relate only to earthly phenomena. Hence, they do not bear comparison with similar assertions of physics and chemistry in this respect, of which the most general ones comply with Maxwell principle of time-space universality. The formal status of most biological generalizations approximates historical (cosmological) generalizations rather than universal laws. This is to be the principal reason for the low evaluation of their explanatory and predictable force.

The suggested ways out of the above impasse are two methodological trends discerned in biology, i.e. reductionism and compositionism. The former envisages a possibility for biology to gain its necessary scientific maturity through turning its laws and theories to physics-chemical generalizations; or it even recommends introducing the laws and theories of physics and chemistry into biological explanations. [Dobzhansky, 1966, Urbanek, 1972] Such an attempt to make the explanatory function of science of life optimal does not seem fruitful, however, if the point is to increase the predictable force of the assertions formulated here. On the other hand it may lead to deprive biology of its autonomy, proper to natural history discipline. On the contrary, the compositionist trend aims at preserving the identity of biology demanding the recognition of both the specified of the subject of its research and the independence of theoretical assertions.

The antireductionist argumentation set forth here seems to indicate at the same time a certain relativity of criteria treated as determining scientific maturity. Among other things, the question concerns here the problem of the level of universality of laws and their predictable values. [Such, 1972]

The duality of cognitive standpoints in biology characterized above does not admit, in my opinion, of siding with any of them univocally in terms of maturity of lack of its determinants in biology. Siding with dualism, on the other hands, steams from the recognition of the substance of postulates both of reductionism 
and compositionism. It is further assured here that biology can accomplish its methodological maturity through the complementary interpreting of both reductionism (physics-chemical) and compositionism (strictly biological) generalizations in its explanations.

The idea of complementary explanation of biology is treated as a general principle of organizing knowledge, analogous to physics [Bohr, 1958]. In order to authenticate in a model of complementary explanation based on the scheme of scientific explanation by $\mathrm{C}$. G. Hempel [1966] was adopted.

Two principal premises are developed in it: a conditional constituent (relating to conditions) and a nomological constituent (relating to theories and laws). W ithin the framework of the former, the hierarchy of levels of the organization of matter is analyzed, whereas the latter aims at the arrangement of the above hierarchy, specified categories of laws and theories. In such a formulation the explanation comprises two intercomplementary components - reductionist "R" and compositionist "K". [Pakszys, 1982, 1983]

Conditions: levels of

integration and of

$\mathrm{Ca}$......., $\mathrm{Cl} . ., \mathrm{Cm} . ., \mathrm{Co} \ldots \ldots \ldots \ldots . \mathrm{Cz}$

organization of matter

elementary particle

atom

molecular system

Theories of:

colloidal aggregate

organellum

cell

tissue

organ individual

group

population

biocenosis

chemistry and

$\mathrm{Te}$..., $\mathrm{Tl}$.., $\mathrm{Tm}$ biochemistry " $\mathrm{R}$ "

molecular

genetics

morpho-anatomy Tl .., Tm .., To physiology

ethology and ecology $\operatorname{Tm} . .$, To ....... Tu

population genetics

evolutional selection

biosphere

$\operatorname{Tm} \ldots$, To

$\mathrm{Tz}$

\section{LEGEND:}

Conditions $\mathrm{Ca}-\mathrm{Cl}$ stand for levels of integration, suquence $\mathrm{Cl}-\mathrm{Cm}$ contain quasiorganizational levels, and $\mathrm{Cm}-\mathrm{Co}-\mathrm{Cz}$ refers to organizational levels where Co stands for the level of the individual. The nomological constituent of complementary explanation includes in its designations only theories $\mathrm{T}$ because laws are their elements (the auxiliary letter symbols are concordant with the notion of proper conditions C). Symbols "R" and "K" stand for reductionist and compositionist component of complementary composed explanation. 
In its primary form the model has been applied to analyze the explanation of two complex biological proccesses, which photosynthesis and respiration are. [Pakszys, 1992a] It has allowed to determine the constituent nomological content of the explanation and the reckon to following theories and laws of physics and chemistry with component " $R$ ": the theory of quantum structure of matter and energy, the laws of thermodynamics, the laws of photoelectronic phenomena, the theory of red-ox reactions, the theory of organic dyes, the theory of the structure of albuminprotein, mono- and polysaccharide, and aliphatic compounds. The distinguished bio-physical and bio-chemical generalizations, like the laws of energetics and enzymes of the living cell, the theory of phosphorylation, the theory of glycolysis, the theory of Kreb's cycle, and others, are treated as the substantiation of adequate theories and physics-chemical laws, the range of which extends onto the cell levels.

The morpho-anatomical and physiological generalizations, showing a structural and functional character, are treated as bordering for components "R" and "K". Among them I reckon the cell theory - of the structure of live organisms, the theory of structure and function of particular tissues, body system, organs, etc.

Among the theories and laws of ethology and ecology, ascribed to component "K" are distinguished those of special structures and functions of adaptable organs, also relating to specific behaviors, like theories of trophism and taxes. The ecological generalizations functioning mainly in collective levels are, among others, the theory of succession in ecosystems and the theory of trophic chains.

It is assumed that all the mentioned biological generalizations, relating to various levels of the organization of life, call for reference to the most general, evolutional theories of selection or "fittest" category. I mean in this place, for instance, enough general, evolutional concepts like stabilizing/varying selection by I. Shmalhauzen [1975],

The substantiation of the model has enabled its verification, revealing at the same time limitations connected with the vegetative character of the examined examples of explanation in biology. Presented here shape of the model includes theories of molecular and population genetics, however, their location - former in " $\mathrm{K}$ " and letter in " $\mathrm{R}$ " - is postulated, hypothetical rather.

It should be stressed that the model of complemetary explanation is an attempts to put into order a certain entirety of interpretative activities of biology, yet it does not lay claims to imposing the goals and determine the directions of research of this discipline.

An attempt carried at the formal characteristics of theories and laws proper to components "R" and "K" of complementary explanation indicates certain similarities of two, in this case extreme types of generalizations, i.e. the laws of microphysics and evolutional selection. These are the most general laws of the 
physical and the life world formulating statistical dependencies and showing a character of idealization. On the other hand, the remaining categories of theories and laws: chemical, biochemical, morphoanatomical, physiological, also ethological and ecological, with the properly narrowed level of universality, can be classified as coexistential, since reflecting jointly structural and functional character. [Krajewski, 1977],

In view of the above, it may be tentatively assumed that there are three principal types of explanation in biology at present: causal-statistical, structural-functional and evolutional-historical.

Later research revealed some other limits of above model. In particular, have been questioned previous connection between components " $R$ " and "K" through morphoanatomical and physiological theories as a challenge to complementarily of both methodologies. In effect there were defined broader and narrow concepts of complementarily. The first concerning general (including biological) cognition, where strategy "R" and "K" represent analysis and synthesis, running through all levels of matter organization in both directions. And second, dealing mainly with biological explanation through particular laws and theories, operating in a shape of two imaginative „cones” connected by the tops representing indicated structural-functional (coexistential) generalizations of the medium levels.

Further considerations have revealed possible historical fundament and actualization together with additional justification of reduction as a logistic procedure, in spite of the controversies concerning Hempelian model of explanation recently. Methodological dualism and complementarily, as well as concrete examples of this strategies in biological explanation supplied some other arguments towards elucidation of the problem of biological (scientific) autonomy. In the light of these biology appeared to be a kind of science not only undergoing but also used to carry on reduction in case of sociobiology. What seems to prove that reductionist - antireductionist opposition and scientific strategy of this sort is not idiosyncratic to this domain only. Hence, rather express frictions between inseparable tendencies of interdisciplinarity and specialization of contemporary scientific cognition of living phenomena.

Compositionism i.e. evolutionism, as an originally developed in biology way of explanation and scientific strategy, seems to be quite uneasy set of procedures to be presented here. I was trying to reconstruct its possible image when starting from rather broad considerations concerning historical development of biological explanation from Aristotelian stationarism, through the modern representatives of transformism, till NeoDarwinian biology today. [Pakszys, 1986, 1988],

If we agree that the latter is usually a form of so-called synthetic theory of life evolution, we shall trace also some ancient steps in the scope of this theory when analyzed below. 
To sketch possible form of contemporary evolutionism I was following, to some extend, the ideas of "'layers" established by I. Lakatos [1978] in his concept of the research programs. But in result of these attempts was established my own way of shaping evolutional explanans. Accordingly, I have tried to prove that we are dealing with a few kinds of theoretical prerequisites in the theory of evolution. For there are present in this "frame" theory certain philosophical presumptions, among which the main one is of life continuity and perfecting, called transformism. What seems related to it is another idea, dressed today in the garb of the organizing levels of living matter. It seems that these two prerequisites possess in its disposal the highest level of generality and persistence, which allows one to assume that it constitute the so-called "hard core" of Neo-Darwinism. It must be also observed, that it is that part of the evolutional research program which cannot, in principle, be questioned from the empirical point of view. And since revealing quite a priori character can be tested at most indirectly.

In the contemporary theory of evolution the philosophical premises mentioned are accompanied by premises of a cosmological and geological character. This set of assumptions is a decisive factor when placing the contemporary conception of the history of life in the wider context of the theories on the evolving Universe. The cosmological theories are usually present in formulating of the changeability concept assumed in every form of evolutionism. We deal here with two main stances: uniformism (or uniformitarism) together with its directive of actualism, and saltationism or neocarastrophism, which is without clear relation towards near past patterns of geological changes.

To put it in general terms, indicated set of premises, especially cos- mo-geological theories seem to present a lower level of universality with regards to the philosophical ones already mentioned. Whereas giving choice to uniformism or saltatyionism in evolutional interpretation, they allow to be treated as a kind of "safety belt" within this research program, as being only relatively constant element of contemporary biological evolutionism. It can further be supposed that both described layers in the theory of evolution - the philosophic and cosmological premises - could constitute a kind of "'general plan" of this theory. This distinction helps to discern Darwinian from Lamarckian attitudes towards changeability in evolutional process. It is accompanied by a co-called "detailed plan" (in the Lakatos languaage this would be the most variable, mutable part of the program, a set of "'auxiliary hypotheses" encompassing all the laws of biology and physicschemistry pertaining in it, when explaining the most varied aspects of life.

We shall sum up above in a schematic diagram of evolutionary explanation ascribed to biology in the following way:

Particular facts;

Theories and Laws of

bio-physics-chemistry

and particular disc.

of biology

Cosmo-geological theories

The theory of organization in Lakatos formulation

a set of

"auxiliary hypotheses" a "detailed plan" 
The composition of the "detailed plan" of the theory of evolution with an interest to us at present is contained in the model of biological explanation formulated earlier. There, with the help of one of the "hard core" theories - the levels in the organization of matter the set of theories and laws taking part in the all evolutional procedure was specified.

An evaluation of the methodological character of the theory of above composition meet with certain difficulties. To one of the more important belongs the nonexistence in science of clearly defined criteria of effectiveness. For, apart from '"longevity", all the other possible conditions of achieving this state can be accused of arbitrariness. The effectiveness of the functioning of a given theory can best be defined in terms of a comparison to a competitive theory. Yet, we do not always have such a possibility at our disposal. As far as the theory of biological evolution in the past half century goes, i.e. since the synthetic theory of evolution was formulated, we are dealing with a situation that is paradoxical from the point of view of e.g. the falsificationistic theory of science by K.R. Popper [1959] - for there is no serious competitor to this issue of Neo-Darwinism. It is the reason why this theory is accused of being of a tautological character i.e. being analytical, like others examples of so called framed theories: Marxism, psychoanalysis.

In this case it seems to be indeed an effect of the "outlinedness" or "frame" character of the theory, embodied in its many-aspects and multi-layers character.

In view of the situation sketched above it must be assumed that it is rather poitless or even impossible to evaluate in full the effectiveness of the theory of life evolution in presented shape. Instead, one could attempt to verify whether such an estimation could be conducted on a fragmentary basis, i.e. with regards to its respective layers and premises.

We shall further assume a possibly universally accepted set of the criteria of effectiveness, which on the whole are identical to the fulfilling of the basic 
22 functions by every scientific theory. We shall therefore attempt to tentatively evaluate the degree to which the elements of the detailed plan and the general plan of the theory of evolution perform the main functions: description, explanation, justification and possibly pre/retrodiction.

We shall begin with an analysis of the detailed plan, or set of bio-physics-chemical and bilogical theories and laws. However, due to the great variety of the present assumptions, the above task would be impossible to perform in the above outlined framework, as it is in effect performed on the ground of the respective biological disciplines. Still, since the problem was the subject of earlier analysis one can assume a state of a satisfactory fulfillment of the most conditions by the assumptions formulating complementary explanans with regards to the respective vegetative phenomena of life. At this point we shall try to analyze the status of only those theories and laws which were not taken into account before i.e. both genetics.

The complementary explanation model in biology encompasses two types of laws of genetics, functioning on two levels - the molecular and the population ones. Such a "forceps" placing of these formulations in the framework of the explanans manifests their key imprtance in the theory. The nature of the regularities described by the laws of molecular genetics are decisive as to the organism's genotype information content. As far as the laws of population genetics go, however, they seem to be a phenotype and statistic expression of the functioning of the genetic code in populations. Therefore, whereas the former, through describing and explaining the raise of hereditary features, the latter enable us to define, to anticipate - with a given amount of probability - the distribution of those features in the populations studied. One can thus assume that, in sum, the laws of both genetics perform the basic functions of description, explanation and of prediction. The degree of their empirical justification should also not raise any reservations. A testimony to which can be found in the great proliferation, in the past decades of literature devoted to the most varies aspects of heredity.

One could also agree with a quite popular opinion, that genetics laws are decisive with regards to the process of the evolution of life. For there is no life without heredity. What raises serious doubts, although, is the bringing down of the whole evolutionary process to the dependencies of genetics, which one sometimes comes across. [Ruse, 1973] It seems, however, that such a view has no sufficient justification. Certainly, the laws and theories of genetics do indeed, in a way, initiate a certain complex process, with which next overlap dependencies constituting a widely understood metabolism. Although, life process overlaps all other regularities discerned on every lavel of matter organization. The dependencies of genetics therefore concern a key, though, only a section of the evolutionary process. All the same, the specific nature of the phenomena they concern, predestinate them surely to attain a special status among other theories and laws of biology.

As regards their methodological character it seems that they are of a mixed nature. In the light of earlier analyses, it would be a cause-and-structural, additionally - at least partly - a statistical type of law. Though, this is only tentative classification still.

We shall now turn to an analysis of the theories constituting the general plan of the biological evolution theory, that is to an evaluation of the cognitive value of its cosmogeological and philosophical premises. 
It was mentioned earlier about a vital opposition, in which uniformism and neocatastrophism seem to remain in geology today. Since each of those theories of the progress in Earth life history phenomena is finding adherents today, our task will be only to evaluate tentativelly the comparative effectiveness of the cognitive values of the both trends.

As far as meeting the criteria of description-explanation and empirical justification goes, it seems that in recent decades we have been dealing with a growing movement away from substantial uniformism in favor of some form of neocatastrophism. It appears, however, that is not easy to relinquish the classical, Lyellan (hence Darwinian) position, since it would remove the basis for the popular, in such cases, inferring by analogy. Since radical acceptance of neo-catastrophism simply does not bring the necessary formula of data interpretation. Still, the problem should be somehow clarified, possibly by finding more distinct connections between catastrophism in geology and the conception of change of the mechanism of evolutionary changes i.e. evolution of life evolution. [Zawadskij, Kolczinskij, 1977],

Attempting now to define the methodological character of such theories, one might assume that they may tentatively be treated as an instance of historical laws (theories) or, better, cosmogeological generalizations [Such, 1972] since referring to the Earth as a part of the Universe.

Let us ponder the idea of transformism and the theory of levels in matter organization to analyze the content of the general plan "core" of life evolution theory.

Transformism, as the oldest form of evolution idea, seems to have its roots in the deep, mythical layers of science and philosophy. Its sense might be expressed shortly in the following way: life as being a process of self-renewing, new incarnations of adult organisms repreducing themselves in young ones, similar, though, often more perfect i.e. better adapted to environment. And such chains of organisms developing in time-space constitute the history of life.

It seems that above formulation of the changeability of living matter may be ascribed to some predecessors and successors of Charles Darwin, together with the theory of levels in the organization of life, which defines generally biological objects structural and functional differentiation [Novikoff, 1945], This theory not only decides about the hierarchy of structures but also enables specification of the progress in the life phenomena. Thus, in a sense, enables predictions. 
As has been suggested earlier, both, the idea of transformism and the theory of organizational levels are distinguished by deeply metaphysical (a priori) character. They seem to constitute some central to biology ontological assumptions. However, it seems also that especially the latter one is not solely an artificial, conventional construct of theoreticians since being quite visibly planted in empiric procedures. Anyway, it exhibits its usefulness in the everyday practice of biologists when enabling them to order (classify) effectively huge factographical material. That does not mean, nevertheless, that as a theoretical construct it would not cause certain problems of a purely formal nature, when, for instance, defining a singular level in this sort of a "ladder of organic beings".

It seems that both theories composing evolutional theory core provide an interpretative framework, useful in informing - describing/explaining - the sequence events in life history on Earth as well as enabling formulation of limited anticipations/predictions in these matters. Although, the problem is different, when we attempt to use the criterium of empirical justification (verification). In this case one may assume that the procedure cannot be conducted directly but only by means of indirect steps, that is through evolutionary premises of a lower order, physics-chemical and biological ones.

At this point one might inquire what is the possible bound between philosophical and cosmo-geological premises in the evolution theory. It seems that the latter constitute a kind of substantiation of ontological conclusions in evolution, inscribing it into conditions on Earth. They, in turn, provide a tentative description of changeability assumed by successive versions of the evolution theory. Equipped with such an "'arsenal", the biologists apply the general plan of this theory to the detailed one, i.e. to the set of mostly empirical assumptions. To create such an image, among other possible, of mutual relations between successive layers of the evolutional research program, the differentiation of both plans was used. For it seems that the concept of changeability as assumed from cosmo-geological premises in an important measure determines the organizing of the biological material to be interpreted.

When it comes to defining the methodological status of the most general, ontological premises of life evolution, it appears that this type of diachronic interpretation should be placed somewhere between two opposite values in research - truth and falsity, i.e. in still little explored spheres of scientific myth.

\section{III}

The problem of the nature of scientific facts remains within the scope of the empirical and naturalistic trends of philosophical reflection on scientific cognition. 
The construction of the basic elements of biological cognition - biological or ''living" facts - can be determined against the historical background of the problem of scientific facts reflected by philosophy of science in 19th to 20th centuries. [Pakszys, 1989], The principal characterization of life phenomena presented below will be compared with the attempts of this kind in the field of theoretical biology, what will serve as the basis for an initial analysis of research methods in biology as representative of contemporary natural sciences.

If to consider a scientific fact being a statement fixing an objective fact (state of affaire) into the system of knowledge, we have in mind neither a subjective fact, nor a "sensedata", but a piece of abstract information concerning reality. Tnen, scientific fact, through abstract notions reflect an object of study undergoing different interpretation i.e. explanation in the light of different theories.

The logical-philosophical reflection of W. V. Quine [1977] and N. Goodman [1977] reveal still the needed congruency of principal intuitions shared by empiricists, when reflecting an attempt at determining conformity between the elements of subjective, expressed in language experience, with real, objective designations: bodies, objects etc. Abstaining here from a detailed analysis of the complicated logistic apparatus, we shall nevertheless try to demonstrate the possibility of applying the Quine-Goodman approach within the scope of reflection concerning biological objects.

The question of biological, 'living" facts is badly in need of additional methodological studies which would show the specificity of both objects and phenomena (processes) qualified as biological. The concept of the fact is an element of the everyday language of researchers, also biological methodologists, but rarely do they reflect on the peculiarity of its application to their field of study. And it is only by gaining an insight into the nature and uniqueness of living objects that one can become aware of the implications of fundamental data concerning life in the whole theoretical construction of biology.

In his attempts to general defining physical from biological W. M. Elsasser [1966] ascribes to non-living phenomena "homogeneity" and to living ones its opposite i.e. 'heterogeneity". One of the few examples of reflection dealing with the fundamental ontological data of biology are remarks by J. Huxley [1948] referring to his concept of synthetic evolution, where three principal aspects of biological data are distinguished: mechanistic-physiological, adaptative-func- tional and historical-evolutional.

J. Monod [1970] considers living objects as being "'autoreproductive machines" and charcterise them with three fundamental, unique properties: tele- onomy, autonomic morphogenesis and reproductive stability.

In presented below general understanding life objects are characterized by three principal aspects: structure, function and self-reproduction. Structure determinesthe basic state of a biological system, the way it is conditioned by time and space, its chemical composition etc. Function, in turn, is derivative of the 
26 structure reflecting active orientation, also a certain order of elements constituting an organic object. Self-reproduction, closely related to structure and function, comprises phenomena that contribute to the originating and generating of organic objects, be it through growth or reproduction.

The indicated primary properties of life can be put together in secondary unions of features: organization, teleonomy and history/evolution. In the following schematic presentation I suggest a set of two triangles placed in opposing directions, where the external one comprises secondary properties of life related accordingly to the internal triangle, representing primary aspects of life.

Such an arrangement of selected features of life may, to an extend, reflect their mutual relationship. The division of "the life triangles" by means of the intermittent line places the diachronic "side" of life phenomena within the range of the history/evolution, and the synchronic one within the vicinity of the organization.

Let us consider, as an example, the problem of organization which is observable in biology. Thus, in the organic world, we encounter a definite hierarchy of levels such as these ascribed to the theory of inorganic and organic matter organization.

The teleonomy for its parts concerns that sphere of life phenomena which is often defined as functional, adaptive or quasi-intentional.

\section{"The Life Triangles"}

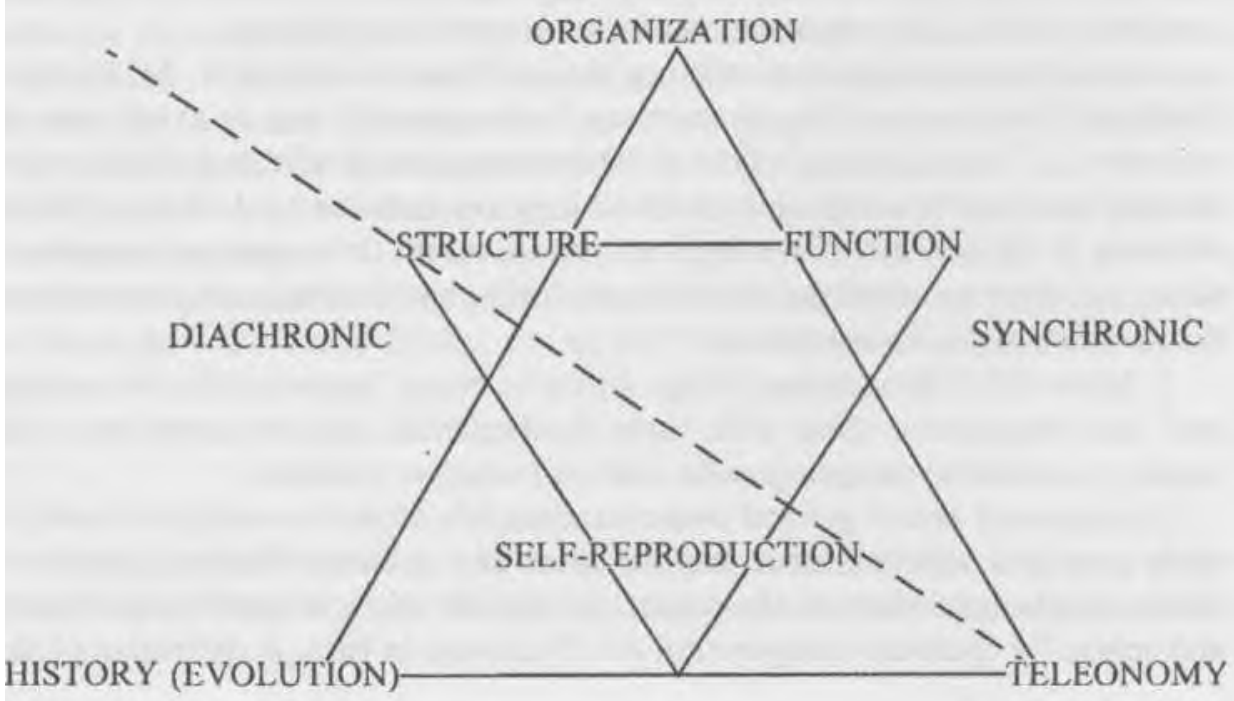


The history/evolution of life, on the other hand, is composed of a whole series of evolutionaily changeable structures and functions whose development depends on both the self-reproduction of organic objects and their teleonomic orientation.

When examining life as a specific form of matter, viz. consider its synchronic side, one usually applies the elements of the theory of organizational levels of matter. However, if our aim is to grasp the changeability and evolutional continuity of life, hence its diachronic side, it is indispensable to take into account a whole set of dependencies concerning function, or, in a broader way, teleonomy and self-reproduction, possibly at all levels of biological complexity. In later reflection there were considered three examples of biological objects, each representing different organizational level - DNA molecule, living cell and population. [Pakszys, 1992 b], Conclusions from this analysis served as an illustration of possible interactions between elements of "life triangles" scheme, what helped to clarify possible relationships of diachronic vs. synchronic interpretations in biology.

A final point need to be made as concerns general view ofthe research methods of biology. Here attentions should be focused on the dualism of reductionist and antireductionist explanation so characteristic to this science. One typical feature of reductionist strategy is making use of dependencies determined for the lower grades of the organization of matter, hence physicochemical in their nature, focusing marked attention on the synchronic side of life. At the same time the diachronic side, characteristic of biological objects is left aside. However, the most desirable, because of its being the most complete, explanation of biological facts seems to be the one related to the diachronic side i.e. to history/evolution. It is only then that synchronic explanation acquire their truly biological value. Hence, even if we can speak of the complementary character of reductionist to antireductionist explanation, the latter seems to keep a distinguished status in biology.

If to consider now the history of the development of life cognition, we may assume that at the earlier stages of biological knowledge the empirical-theoretical method was prevalent in research. Given insufficient evidence of elementary character, common facts came into play; they were not yet interpreted in the light of science as we know it today, though they were usually furnished with some symbolic interpretation (magic or religious).

In the course of improving the methods of observing nature and consequently enriching the set of data concerning organic matter, the primary interpretations (most often creationistic and synchronic) turn out to be insufficient. This forced researchers to formulate new laws and theories, though of a more naturalistic character. On the contrary then, in contemporary biology, in view of the considerable accumulation of basic facts and great theoretical advancement, one should rather expect a theoretical-empirical method if cognition.

28

Can it be assumed that biologist deal with a cognition consistent with the hypotheticodeductive method so characteristic of the theoretically advanced physico-chemical trend in the natural sciences?This method can be ascribed to at least some constituent elements 
of the theory of evolution, such as population genetics, or in theoretical molecular biology (hypercycle). Also on sociobiologi- cal ground, the same problem was dealt with in the course of projecting the new research method for the discipline presenting a kind of usurpation towards the humanities. Although, the problem appears occasionally, for the time being, the contribution of inductive research procedure to the whole construction of this field remains significant still. And it is in this sense that the determination of the mutual relationship between the empirical foundations and the theoretical considerations of biology continues to be an open issue still.

\section{REFERENCES}

N. Bohr, 1958, Atomic Pysics and Human Knowledge, New York (in Polish: Biologia a fizyka atomowa, Warsaw 1963).

Th. Dobzhanski, 1966, Are Naturalists Old Fashioned, „The American Naturalist” (in Polish: Kartezjanskie i Darwinowskie aspekty biologii „Problemy” no 10, 1966).

M. Eigen, P. Schuster, 1979, The Hypercycle, A Principle of Natural Selforganization, Berlin- -New York.

M. Eliade, 1974, The Myth of Eternal Return, or Cosmos and History, New York.

W. M. Elsasser, 1966, Atom and Organism, A New approach into Theoretical Biology, Princeton.

N. Goodman, 1977, The Structure of Appearance, Dordrecht-Boston.

C. G. Hempel, 1966, Philosophy of Natural Science, New Jersey (Podstawy nauk przyrodniczych, Warsaw 1973).

J. S. Huxley, 1948, Evolution the Modern Synthesis, London.

Wl. Krajewski, 1977, Konieczność - Przypadek - Prawo Statystyczne (Necessity- Random - Statistical Law), Warsaw.

K. Lakatos, 1978, The Methodology of Scientific Programs, Pilosophical Papers vol. 1, Cambridge. J. Monod, 1970, Le hasard et le necessite, Paris.

A.B. NovikolT, 1945, The Concept of Integrative Levels in Biology, „Science”, vol. 101.

E. Pakszys, 1982, Wyjaśnianie komplementarne w biologii (Complementary Explanation in Biology), „Poznańskie Studia z Filozofii NaukF’no 7.

E. Pakszys, 1983, Racjonalność współczesnej biologii: redukcjonizm contra kompozycjonizm czy komplementarność (Rationality of Contemporary Biology: Reductionism vs. Com- positionism or Complementarily), „Studia Filozoficzne”, no 5-6.

E. Pakszys, 1986, Filozoficzne i przyrodnicze uwarunkowania rozwoju teorii ewolucji biologicznej (Philosophical and Naturalist Conditions in Development of Biological Theory of Evolution) in: Szkice o rozwoju nauki (Essays on Science Development), Poznań.

E. Pakszys, 1988, The Cognitive Status of the Theory of Evolution in Contemporary Biology, in: Laws and Theories in Empirical Sciences, Poznań.

E. Pakszys, 1989, The Problem of Scientific facts: „Living” Facts in the Light of Biological Theories, in Reports of the 13th Int. Wittgenstein Symposium, vol. 18.

E. Pakszys, 1992, Problemy dualizmu metodologicznego współczesnej biologii, (The Problems of Contemporary Biology Methodological Dualism) in: Nauka w świetle współczesnej filozofii, Warsaw.

E. Pakszys, 1992 a, Redukcjonizm fizyko-chemiczny współczesnej biologii (Physico-chemical Reductionism of Contemporary Biology) „Studia Metodologiczne” no 27, Poznań.

E. Pakszys, 1992 b, Probleme der Theorie biologischer Objecte, in: Zur Fragen der heutigen theorie und Method ologie der wissenschftlichen Erkennlnis, Poznan.

K. R. Popper, 1959, The Logic of Scientific Discovery, (Polish ed. Warsaw 1977). 
K.R. Popper, 1984, The Poverty of Historicism, (Polish ed. Warsaw).

W. V. Quine, 1977, Facts of the Matter, American Philosophy from Edwards to Quine, Norman. M. Ruse, 1973, The Philosophy of Biology, London.

M.A. Simon, 1971, The Matter of Life, Philosophical Problems of Biology, London.

I. 1. Shmalhauzen, 1975, The Factors of Evolution, The Theory of Stabilizing Selection (tansl. from Russian), Warsaw.

J. Such, 1972, O uniwersalności praw nauki (On Universality of Laws of Science), Warsaw.

A. Urbanek, 1973, Rewolucja naukowa w biologii (Scientific Revolution in Biology), Warsaw.

K. M. Zawadskij, E.1. Kolczinskij, 1977, The Evolution of Evolution, Leningrad. 